\title{
What Place for New Protocols Regimen in Controlled Ovarian Hyperstimulation $(\mathrm{COH})$ Before IVF?
}

\author{
Nathalie Massin* \\ Procreation Medical Assistance Center, Intercommual Hospital Center, France \\ Submission: October 01, 2017 ; Published: November 26, 2018 \\ *Corresponding author: Nathalie Massin, Procreation Medical Assistance Center, Intercommual Hospital Center, France
}

\section{Opinion}

With the improvement of cryopreservation of embryos and oocytes, the frontiers of conventional ovarian stimulation are being pushed away (Massin 2017). More and more IVF attempts lead to freeze only with transfer in a subsequent cycle. Warming of embryos after vitrification give near $100 \%$ of survival rate, far more (Rienzi et al. 2010), than with the abandoned slow freezing technique. Evidence accumulates about the impairment of endometrium and decrease of implantation rate after $\mathrm{COH}$, especially with high endogenous steroids levels at triggering of ovulation (estradiol and progesterone). More and more published data corroborate to show that freezing an entire cohort of embryos, does not compromise but improve the results of IVF cycles (Roque et al. 2015) and may also improve neonatal issues XXX with the embryo transfer performed in a natural cycle. As the standard sequence "stimulation-retrieval-transfer" can be avoided, the hormonal constraints associated with the fresh transfer don't stand anymore.

Once, progesterone in follicular phase and especially during ovarian stimulation was consider the enemy of the IVF specialist. But the oocyte donor model and the freeze only strategies have demonstrated that the negative impact of progesterone is only on endometrial receptivity and that there is no impact on oocyte quality. Besides, initial physiologic studies have demonstrated that progesterone modulates GnRH secretion by decreasing GnRH pulse frequency (hypothalamic action) (Chabbert-Buffeta et al. 2000) and that progestin inhibits physiologic LH surge induced by estradiol (Heikinheimo et al. 1996). Furthermore, Baer Wald and coll (Baerwald, Adams, et Pierson 2003) have shown that 2 or 3 follicular waves exist within a menstrual cycle, the one emerging in the early follicular phase being ovulatory, and others anovulatory. Put together, we understand that FSH stimulation can start irrespective of the cycle day and that progesterone, either endogenous or exogenous, may replace the GnRH agonist or antagonist to block the LH surge. There are growing evidence confirming that a progestin -medroxyprogesterone acetate (Kuang et al. 2015), natural micronized progesterone (Zhu, Ye, et Fu 2016)- or endogenous progesterone in luteal phase (Wang et al. 2016) inhibits the LH surge during FSH stimulation, without impairing response to triggering by HCG or GnRH agonist (Kuang et al. 2015). The number, the competence and the risk of aneuploidy (Ubaldi et al. 2016) of oocytes obtained under progesterone are comparable with the ones obtained by conventional stimulation. The implantation rate of the frozen-warmed embryos obtained from these oocytes confirms the quality of embryos obtained. Neonatal issues seem also reassuring (H. Chen et al. 2015).

\section{These new protocols regimen include}

luteal phase stimulation where FSH starts in the early luteal phase, without any other drug than $\mathrm{FSH}$; progestin primed ovarian stimulation where FSH starts at cycle day 1 to 3 with concomitant progestin; random start stimulation where FSH starts whenever the cycle day with or without progestin depending on the cycle day, usually in urgent fertility preservation in cancer patient; duostim where a first stimulation and retrieval is performed in follicular phase and a second stimulation is performed in the luteal phase just after the first retrieval ( 2 stimulations within one cycle).

These emerging protocols seem promising especially in case of programmed oocyte or embryo cryopreservation such as fertility preservation for cancer or non-cancer patient, oocyte donation or other situation where $\mathrm{COH}$ impaires fresh implantation rates such as polycycstic ovary syndrome (Z.-J. Chen et al. 2016). They enable more flexibility for the patients and the physician. They seem to be also safely used for normal responders or poor responders. But the medical and economic significance of these protocols still remain to be demonstrated with randomized controlled trial and medico-economic studies with a larger number of patients. If the existing data are confirmed, these protocols will certainly spread in the general population of IVF patients. 
(C) This work is licensed under Creative

BY DOI: 10.19080/JGWH 2018.13.555853
Your next submission with Juniper Publishers will reach you the below assets

- Quality Editorial service

- Swift Peer Review

- Reprints availability

- E-prints Service

- Manuscript Podcast for convenient understanding

- Global attainment for your research

- Manuscript accessibility in different formats ( Pdf, E-pub, Full Text, Audio)

- Unceasing customer service

Track the below URL for one-step submission https://juniperpublishers.com/online-submission.php 